\title{
Characterization of Sorghum and Millet with Special Reference to Fatty Acid and Volatile Profile.
}

\author{
Muhammad Farhan Jahangir Chughtai ${ }^{1}$, Imran Pasha ${ }^{1}$, Faqir Muhammad Anjum ${ }^{2}$, \\ Muhammad Adnan Nasir ${ }^{1}$
}

${ }^{1}$ National Institute of Food Science \& Technology, Faculty of Food, Nutrition \& Home Sciences, University of Agriculture Faisalabad, Punjab-Pakistan ${ }^{2}$ Department of Food Science \& Home Economics, Govt. College University, Faisalabad, Punjab-Pakistan

A R T I C LE INFO

Article history:

Received 26 November 2014

Accepted 07 January 2015

Available online, ISSN: 2148-127X

Keywords:

Cereals

Characterization

Fatty acids

Millet

Sorghum

Volatile profile

\section{${ }^{*}$ Corresponding Author:}

E-mail:

m.farhan.chughtai@hotmail.com
A B S T R A C T

Sorghum and millet are important food staples in semi-arid tropics of Asia and Africa. Sorghum and millet are cereal grains that have prospective to be used as substitute to wheat flour for celiac patients. These are considered as the good source of many important and essential fatty acids. The volatile profiling of these two important crops is comparable to other cereals as well. The present study was an effort to explore biochemical composition of commercially available sorghum and millet varieties with special reference to their fatty acid and volatile profiling. Chemical composition of sorghum and millet was determined according to respective methods. Fatty acid methyl esters were prepared and then subjected to GC-FID for fatty acids analysis. The results indicated that both sorghum and millet oils are rich in essential fatty acids comprising mono and polyunsaturated fatty acids. Main fatty acids that are identified in current study includes palmitic acid, oleic acid, palmitoleic acid, behenic acid, linoleic acid, linoleic acid, stearic acid, myristic acid, etc. On the other hand volatile compounds from sorghum and millet were determined by preparing their respective volatile samples by using calvenger apparatus with suitable volatile extracting solvent. Volatile samples were then subjected to GC-MS analysis and respected results were compared with NIST library. About 30 different volatiles were identified in millet varieties while 35 different compounds were discovered in sorghum varieties belonging to aldehydes, ketones, benzene derivatives, esters, alcohols, sulphur compounds.

\section{Introduction}

Food is one of the basic necessities of mankind and is obtained from different sources such as cereals, meat, vegetables, fruits, milk and milk products. Cereals represent major staple foods as they supply large quantity of energy, carbohydrates, protein, micronutrients and fiber to the human diet in developing countries (Sikwese and Duodo, 2007). Sorghum and millet are primary sources of nutrients e.g. protein, mineral, vitamins and energy (Belton and Taylor, 2004). Sorghum is ranked as the 5th most important and valuable crop worldwide after wheat, corn rice and barley is a tropical plant belonging to the Poaceae family (Awika and Rooney, 2004). While Pearl millet (Pennisatum glaucam) is cultivated on about 12 million hectares and 15 million hectares in Asia and Africa respectively, consumed as the staple food by a large number of population in India and Africa (Maha et al., 2003). According to the latest researches, an increased interest in usage of finger millet is observed. Potential health benefits includes hypoglycemic features, antioxidant, and antimicrobial activities which are due to its polyphenols (Lakshmi et al., 2002; Chethan and Malleshi, 2007).
Oil extracted from the various cereal grains has peculiar fatty acids with characteristic properties which are important from industrial point of view. The main fatty acids contributing in the human physiology by various ways are saturated, mono and polyunsaturated fatty acids abbreviated as SFA, MUFA and PUFA respectively (Iso et al., 2002; Patil and Gisler, 2006). Most concerned fatty acids are linoleic acid and linolenic acid since both are vital for humans and previous researches have shown that linoleic was the prime fatty acid in sorghum and millet varieties, followed by palmitic acid and oleic acid. The key fatty acid constituents in the oil of sorghum seeds were palmitic (C-16:0), oleic (C18:1) and linoleic (C-18:2) acids. Moreover unsaturated fatty acid comprises of linolenic acid (C-18:3) and palmitoleic acid (C-16:1) existing in several varieties (Mehmood et al., 2008). According to the research results concentrations of stearic acid, palmitic acid and arachidic acid is (1.2 to $1.4 \%),(12.1-13.4 \%)$ and (0.1-0.2\%) respectively. Palmitic and arachidic acid were the highest amound fatty acids in some varieties. While Afify et al. (2012) have found that sorghum contains stearic acid 
$(1.1-2.6 \%)$ and palmitic acid (12.0-20.2\%). Whereas Pontieri (2011) have declared that palmitic acid (11.9$14.2 \%)$ and arachidic acid (0.1-0.3\%) were present in the seed oil of various sorghum varieties.

Mehmood et al. (2008) have found that sorghum varieties contain linoleic acid and oleic acid as major unsaturated fatty acids when analyzed. According to Rooney and Waniska (2000), fatty acids composition of seed oil have declared that the Sorghum bicolor seed oils serve as a potential dietary source of MUFA and PUFA.

The main volatile compounds of cereals include aldehydes, ketones, hydrocarbons, benzene derivatives, alcohols, esters, acids, heterocycles and sulphur. Very little information is available regarding volatile compounds of millet and sorghum. About 50 different types of volatile compounds in millet (Jingke et al., 2012) and among them aldehyde and benzene derivatives were the main compounds in millet. The largest volatile compounds group is aldehyde group in all the identified components. Benzene components were the second most important volatile components. Alcohols, heterocycles, ketones and sulphur compounds were present in minor amounts in aroma compounds of millet (Iso et al., 2002; Jingke et al., 2012).

\section{Materials and Methods}

\section{Procurement of raw material}

Seven commercially available varieties of sorghum i.e. Chengari, F-114, JS-263, JS-2002, MR-Sorghum, PC1 and Sandal Bar and two varieties of millet i.e. MB-87 and Sargodha Bajra 2011 were purchased from Ayub Agricultural Research Institute, Faisalabad. Chemicals were purchased from Sigma Aldrich, Labscan etc.

\section{Chemical analysis}

The flour of sorghum and millet varieties were evaluated for proximate composition i.e. moisture, ash, crude fat, crude fiber and protein according to the AACC 2000 method.

\section{Fatty acid analysis}

Oil from the sorghum and millet was extracted by Soxhlet apparatus using petroleum ether as extraction solvent. The extracted oil was converted into fatty acids methyl esters by using the method adopted by Ryan et al. (2007). By using Pasteur pipettes transferred $100 \mathrm{mg} \pm 5 \mathrm{mg}$ of oil sample to the pyrex test tube with a tight sealing cap. In order to dissolve lipids, added $5 \mathrm{ml}$ of hexane and afterwards briefly vortexed. Followed by the addition of $250 \mu \mathrm{l}$ sodium methoxide reagent in the capped test tube and vortex for one minute, pausing every 10 seconds to allowed the vortex to collapse. Added $5 \mathrm{ml}$ of saturated $\mathrm{NaCl}$ from Rci Labscan to the test tube, capped the test tube and Shake vigorously for $15 \mathrm{sec}$. Let stand for 10 minutes. After that removed the hexane layer and transferred to a vial containing a small volume of Sodium sulphate from Sigma aldrich. FAME should remain in contact with hexane layer having sodium sulphate at least 15 minutes before GC analysis. Transferred the hexane layer to a vial for subsequent GC analysis. GC (Agilent 6890) is used for Fatty acid methyl esters analysis equipped with Flame Ionization Detector as described by Ryan et al. (2007). Following conditions were used for the GC analysis: column, DB wax Capillary; $60.0 \mathrm{~m}$ $\times 0.25 \mathrm{~mm} \times 0.251 \mathrm{~m}$; oven temperature programme, the column held initially at $60^{\circ} \mathrm{C}$ for $3 \mathrm{~min}$ after injection, then increased to $185^{\circ} \mathrm{C}$ with $10^{\circ} \mathrm{C} / \mathrm{m}$ in heating ramp for $1 \mathrm{~min}$ and increased to $200^{\circ} \mathrm{C}$ with $5^{\circ} \mathrm{C} / \mathrm{min}$ heating ramp for $10 \mathrm{~min}$. Then the final temperature was increased to $220^{\circ} \mathrm{C}$ with $5^{\circ} \mathrm{C} / \mathrm{m}$ in heating ramp for $20 \mathrm{~min}$; injector temperature, $250^{\circ} \mathrm{C}$; detector (FID) temperature, $275^{\circ} \mathrm{C}$; carrier gas, Nitrogen; inlet pressure, $40.65 \mathrm{psi}$; linear gas velocity, $39 \mathrm{~cm} / \mathrm{s}$; column flow rate , $2.7 \mathrm{ml} / \mathrm{m}$ in; split ratio, 40:1; injected volume, $1 \mu \mathrm{L}$.

\section{Volatile compounds analysis}

Volatile compounds from sorghum and millet flours were extracted by using Clevenger apparatus according to the method of Damjan et al. (2009). In this method flour sample of $250 \mathrm{~g}$ of sorghum and millet grains and 21 distilled water was placed in a 41 flask for 30 minutes. After that flour sample was transferred into Clavenger apparatus. Dichloromethane from Sigma Aldrich was used as the extraction solvent. The samples were heated for 4 hours. After that samples were cooled and dichloromethane was separated in flasks. After that dichloromethane was evaporated by using rotary evaporator. After evaporation the concentrated samples were transferred into vials having small amount of sodium sulphate. The samples were then subjected to GC (Agilent 6890) Coupled with Mass Detector (Agilent 5973).

Following specifications were used for the volatile analysis. Column: VOCOL, $60 \mathrm{~m} \times 0.25 \mathrm{~mm}$ (i.d.), film thickness $1.5 \mu \mathrm{m}$ (Supelco, Bellefonte, PA, USA). Temperature programmed as: starting at $50^{\circ} \mathrm{C}(2 \mathrm{~min})$, heating at $5^{\circ} \mathrm{C} \min ^{-1}$, final temperature $210^{\circ} \mathrm{C}$ (40 min). Tinj: $250^{\circ} \mathrm{C}$; Tdet : $280^{\circ} \mathrm{C}$; injection volume: $1 \mu 1$. Carrier gas: He, flow $1 \mathrm{ml} \mathrm{min-1.} \mathrm{MS} \mathrm{conditions} \mathrm{were} \mathrm{set} \mathrm{in} \mathrm{a}$ way that: electron impact mode, total ion current (TIC) recorded. NIST spectral library was used to compare the mass spectra of compounds subjected to analysis. Damjan et al., 2009).

\section{Results and Discussion}

\section{Proximate composition}

Chemical composition for different varieties of Sorghum and Millet have been shown in table 1 and table 2. The moisture content was ranged from 5.4 to $10.0 \%$ in different varieties of sorghum and 8.1 to $9.3 \%$ in millet varieties. Ash content ranged from 1.6 to $3.3 \%$ in sorghum and 1.5 to $2 \%$ in millet. Crude fat ranged from 2.5 to $5.6 \%$ in whole flour of different varieties of sorghum and 3.7 to $3.8 \%$ in millet. Crude fiber showed minimum value of $2.6 \%$ and the maximum value of $3.9 \%$ for sorghum. Crude fiber exhibited the minimum value of $2.2 \%$ and the maximum value of $2.9 \%$ for millet. Crude protein in different varieties of sorghum ranged from 11.9 to $17.0 \%$ and 15.7 to $16.1 \%$ in millet. Nitrogen free extract (NFE) in different varieties of sorghum was ranged from 64.9 to $69.7 \%$. NFE in different varieties of millet was ranged from 67.3 to $66.8 \%$. 
Table 1 Mean Values for proximate of sorghum varieties

\begin{tabular}{l|lllllll}
\hline Sr.No. & Varieties & Moisture Contents & Ash Content & Fat Content & Fiber Content & Protein Content & (NFE) \\
\hline 1 & F-114 & $10.0^{\mathrm{a}}$ & $1.8^{\mathrm{d}}$ & $3.3^{\mathrm{cd}}$ & $3.1^{\mathrm{bc}}$ & $12.6^{\mathrm{d}}$ & $69.7^{\mathrm{a}}$ \\
2 & Chengari & $9.0^{\mathrm{b}}$ & $3.3^{\mathrm{a}}$ & $5.6^{\mathrm{a}}$ & $3.3^{\mathrm{ab}}$ & $11.9^{\mathrm{d}}$ & $66.6^{\mathrm{bc}}$ \\
3 & SB & $8.6^{\mathrm{bc}}$ & $2.7^{\mathrm{ab}}$ & $2.5^{\mathrm{d}}$ & $3.2^{\mathrm{abc}}$ & $17.0^{\mathrm{a}}$ & $64.9^{\mathrm{c}}$ \\
4 & JS-263 & $8.3^{\mathrm{c}}$ & $1.6^{\mathrm{d}}$ & $4.5^{\mathrm{b}}$ & $3.9^{\mathrm{a}}$ & $15.3^{\mathrm{b}}$ & $66.3^{\mathrm{c}}$ \\
5 & MR & $6.7^{\mathrm{d}}$ & $2.1^{\mathrm{cd}}$ & $4.7^{\mathrm{ab}}$ & $2.6^{\mathrm{c}}$ & $14.0^{\mathrm{c}}$ & $69.6^{\mathrm{a}}$ \\
6 & PC-1 & $6.7^{\mathrm{d}}$ & $3.0^{\mathrm{ab}}$ & $3.9^{\mathrm{bc}}$ & $3.0^{\mathrm{bc}}$ & $14.3^{\mathrm{bc}}$ & $68.8^{\mathrm{a}}$ \\
7 & JS-2002 & $5.4^{\mathrm{e}}$ & $2.6^{\mathrm{bc}}$ & $5.4^{\mathrm{a}}$ & $3.4^{\mathrm{ab}}$ & $14.5^{\mathrm{bc}}$ & $68.3^{\mathrm{ab}}$ \\
\hline
\end{tabular}

Mean carrying same letters are significantly identical.

Table 2 Mean Values for proximate of millet varieties

\begin{tabular}{l|lllllll}
\hline Sr.No. & Varieties & Moisture Contents & Ash Content & Fat Content & Fiber Content & Protein Content & NFE \\
\hline 1 & MB-87 & $9.3^{\mathrm{a}}$ & $1.5^{\mathrm{b}}$ & $3.7^{\mathrm{a}}$ & $2.2^{\mathrm{a}}$ & $15.7^{\mathrm{a}}$ & $67.3^{\mathrm{a}}$ \\
2 & S-2011 & $8.1^{\mathrm{b}}$ & $2.0^{\mathrm{a}}$ & $3.8^{\mathrm{a}}$ & $2.6^{\mathrm{c}}$ & $16.1^{\mathrm{a}}$ & $66.8^{\mathrm{a}}$ \\
\hline
\end{tabular}

Mean carrying same letters are significantly identical.

\section{Fatty acids analysis of millet and sorghum oil}

Fatty acid analysis of oil from millet varieties: Fatty acids methyl esters of samples were loaded on a DBWAX column, FID as detector and fractionated by "Gas Chromatography". Two varieties of millet i-e MB-87 and Sargodha Bajra-2011 were subjected to FAME analysis. The fatty acids composition of these two varieties of millet oil is presented in Table 3. The analysis has shown that the most abundant fatty acid found in both millet varieties is linoleic acid followed by oleic, palmitic and stearic acid. The fatty acid composition of S. Bajra-2011 includes linoleic acid, oleic acid, palmitic acid, erucic acid, stearic acid, arachidic acid, linolenic acid and myristic acid with their concentration in $\mathrm{mg} / \mathrm{g}$ are as $30.38982,16.04982,6.319236,2.19719,1.402741$, $0.111822,0.404938$ and 0.232085 respectively. Whereas the different fatty acids present in MB-87 includes linoleic acid, oleic acid, palmitic acid, behenic acid, stearic acid, linolenic acid, eicosaenoic acid, myristic acid arachidic acid and their concentration in $\mathrm{mg} / \mathrm{g}$ are as $20.71603,13.12652,4.613243,1.327375,1.304543$, $0.325811,0.315462,0.214316$, respectively. Unsaturated fatty acids are more in concentration as compared to saturated fatty acids. Millet varieties are rich in concentration of mono and polyunsaturated fatty acids. The results obtained were in accordance to the research work of Liang et al. (2010) and Amadou et al. (2011).

Fatty acid analysis of oil from sorghum varieties: The following seven varieties of sorghum were subjected to fatty acid analysis. The varieties are MR-Sorghum, Sandal Bar, PC-1, JS-2002, JS-263, F-114 and Chengari. The fatty acids composition of these varieties is presented in Table 4. The analysis has shown that the most abundant fatty acid found in all varieties is linoleic acid followed by palmitic acid, oleic acid and stearic acid. The results obtained are in accordance with the research outcomes of Mehmood et al. (2008) and Abugri et al. (2013).

The fatty acid composition of Sandal Bar includes palmitic acid, linolenic acid, linoleic acid, oleic acid, stearic acid, palmitoleic acid, arachidic acid and with their concentration in $\mathrm{mg} / \mathrm{g}$ are as 20.04547, 15.49279, $11.04548, \quad 6.764472, \quad 1.986131,0.406898,0.399018$ respectively. Fatty acids present in Chengari includes linoleic acid, oleic acid, palmitic acid, stearic acid, linolenic acid, behenic acid, arachidic acid, palmitoleic acid and their concentration in $\mathrm{mg} / \mathrm{g}$ are as 32.57048, 26.05815, 8.680313, 2.05107, 1.750787, 0.816, 0.642986, 0.268352 respectively. The results obtained are in accordance with the research outcomes of Mehmood et al. (2008) and Abugri et al. (2013).

However the fatty acid composition of PC-1includes palmitic acid, oleic acid, linolenic acid, linoleic acid, caprylic acid, stearic acid, palmitoleic acid, arachidic acid and with their concentration in $\mathrm{mg} / \mathrm{g}$ are as 20.31206, 15.31234, 10.33762, 6.490962, 5.142434, 0.399018, 0.203304 respectively. The fatty acid composition of MRSorghum includes palmitic acid, linolenic acid, linoleic acid, oleic acid, stearic acid, palmitoleic acid, arachidic acid and with their concentration in $\mathrm{mg} / \mathrm{g}$ are as 20.04547, 15.49279, 11.04548, 6.764472, 1.986131, $0.406898,0.399018$ respectively. The results obtained are in accordance with the research outcomes of Mehmood et al. (2008) and Abugri et al. (2013).

On the other hand fatty acid profile and concentration of JS-263 includes palmitic acid, linolenic acid, linoleic acid, oleic acid, lauric acid, tri-decanoic acid, behenic acid, stearic acid, palmitoleic acid, arachidic acid and with their concentration in $\mathrm{mg} / \mathrm{g}$ are as 21.42487, 21.1333, 15.49279, 8.665198, 6.809967, 1.833253, $1.11989,0.571411$ and 0.106262 respectively. Fatty acids present in JS-2002 includes linoleic acid, oleic acid, palmitic acid, linolenic acid, pentadecanoic acid, heptadecanoic acid, behenic acid and their concentration in $\mathrm{mg} / \mathrm{g}$ are as $10.11821,8.665198,6.319236,6.293466$, $2.861636,1.468547,1.327375$ respectively. The results obtained are in accordance with the research outcomes of Mehmood et al. (2008) and Abugri et al. (2013). 
Table 3 Fatty acid composition of Millet varieties

\begin{tabular}{|c|c|c|c|c|}
\hline Serial No. & Fatty acid & Carbon \# & MB-87 & S.Bajra 2011 \\
\hline 1 & Caprylic acid & $\mathrm{C}: 8$ & -- & -- \\
\hline 2 & Capric acid & $\mathrm{C}: 10$ & -- & -- \\
\hline 3 & Lauric acid & $\mathrm{C}: 12$ & -- & -- \\
\hline 4 & Tri-decanoic acid & $\mathrm{C}: 13$ & -- & -- \\
\hline 5 & Myristic acid & C: 14 & 0.315462 & 0.232085 \\
\hline 6 & Myristoleic acid & C:14:1 & -- & -- \\
\hline 7 & Pentadecanoic acid & $C: 15: 0$ & -- & -- \\
\hline 8 & Palmitic acid & $C: 16: 0$ & 4.613243 & 6.319236 \\
\hline 9 & Palmitoleic acid & $C: 16: 1$ & -- & -- \\
\hline 10 & Heptadecanoic acid & $\mathrm{C}: 17: 0$ & -- & -- \\
\hline 11 & Stearic acid & $\mathrm{C}: 18: 0$ & 1.304543 & 1.402741 \\
\hline 12 & Oleic acid & C: $18: 2$ & 13.12652 & 16.04982 \\
\hline 13 & Linoleic acid & C: $18: 2$ & 20.71603 & 30.38982 \\
\hline 14 & Arachidic acid & C:20:0 & 0.111822 & 0.111822 \\
\hline 15 & Eicosaenoic acid & $C: 20: 1$ & 0.214316 & 0.226012 \\
\hline 16 & Linolenic acid & $C: 18: 3$ & 0.325811 & 0.404938 \\
\hline 17 & Behenic acid & $C: 22: 0$ & 1.327375 & -- \\
\hline 18 & Erucic acid & C:22:1 & -- & 2.19719 \\
\hline
\end{tabular}

Table 4 Fatty acid contents of different sorghum varieties

\begin{tabular}{|c|c|c|c|c|c|c|c|c|c|}
\hline Serial No. & Fatty acid & Carbon \# & Chengari & JS-2002 & JS-263 & F-114 & PC-1 & $\begin{array}{c}\text { MR- } \\
\text { Sorghum }\end{array}$ & $\begin{array}{c}\text { Sandal } \\
\text { Bar }\end{array}$ \\
\hline 1 & Caprylic acid & $\mathrm{C}: 8$ & -- & -- & -- & -- & 6.490962 & -- & -- \\
\hline 2 & Capric acid & $C: 10$ & -- & -- & -- & -- & -- & -- & -- \\
\hline 3 & Lauric acid & $C: 12$ & -- & -- & 6.809967 & -- & -- & -- & -- \\
\hline 4 & Tri-decanoic acid & C: 13 & -- & -- & 1.833253 & -- & -- & -- & -- \\
\hline 5 & Myristic acid & $C: 14$ & -- & -- & -- & -- & -- & -- & -- \\
\hline 6 & Myristoleic acid & $C: 14: 1$ & -- & 5.853584 & -- & -- & -- & -- & -- \\
\hline 7 & Pentadecanoic acid & $C: 15: 0$ & -- & 2.861636 & -- & -- & -- & -- & -- \\
\hline 8 & Palmitic acid & $C: 16: 0$ & 8.680313 & 6.319236 & 21.42487 & 7.68082 & 20.31206 & 20.04547 & 20.28759 \\
\hline 9 & Palmitoleic acid & $C: 16: 1$ & 0.268352 & -- & 0.106262 & 0.268352 & 0.399018 & 0.399018 & -- \\
\hline 10 & Heptadecanoic acid & $C: 17: 0$ & -- & 1.468547 & -- & -- & -- & -- & -- \\
\hline 11 & Stearic acid & $C: 18: 0$ & 2.05107 & -- & 0.571411 & 2.05107 & 5.142434 & 1.986131 & 3.187229 \\
\hline 12 & Oleic acid & $C: 18: 2$ & 26.05815 & 8.665198 & 8.665198 & 0.109203 & 15.31234 & 6.764472 & 24.90237 \\
\hline 13 & Linoleic acid & $C: 18: 2$ & 32.57048 & 10.11821 & 21.1333 & 13.11945 & 10.33762 & 11.04548 & 40.37136 \\
\hline 14 & Arachidic acid & $C: 20: 0$ & 0.642986 & -- & -- & 0.764418 & 0.203304 & 0.406898 & 0.406898 \\
\hline 15 & Eicosaenoic acid & $C: 20: 1$ & 1.442999 & -- & -- & 3.2255 & 1.566329 & -- & 0.303668 \\
\hline 16 & Linolenic acid & $C: 18: 3$ & 1.750787 & 6.293466 & 15.49279 & 0.387244 & -- & 15.49279 & 0.407188 \\
\hline 17 & Behenic acid & $C: 22: 0$ & 0.816 & 1.327375 & 1.11989 & -- & -- & -- & -- \\
\hline 18 & Erucic acid & $C: 22: 1$ & -- & -- & -- & -- & -- & -- & -- \\
\hline
\end{tabular}

Fatty acids present in F-114 includes linoleic acid, palmitic acid, eicosaenoic acid, stearic acid, arachidic acid, linolenic acid, palmitoleic acid, oleic acid their concentration in $\mathrm{mg} / \mathrm{g}$ are as $13.11945,7.68082,3.2255$, $2.05107, \quad 0.764418, \quad 0.387244, \quad 0.268352, \quad 0.109203$ respectively. The results obtained are in accordance with the research outcomes of Mehmood et al. (2008) and Abugri et al. (2013).

\section{Volatile compounds of sorghum and millet}

The volatile compounds from Sorghum and millet varieties were extracted by using the Clevenger apparatus method and detected by using GC-MS. The results obtained were identified from NIST library. A total of 30 volatile compounds were identified in millet varieties. These compounds included aldehydes, benzene derivatives, ketones, alcohols, esters, hydrocarbons, acids, furans and S-containing compounds. On the other hand 35 volatiles compounds were identified in seven varieties of sorghum. The results are presented in below in respected Table $5 \& 6$ of Millet and Sorghum.

Volatile compounds of millet: Aldehydes were the main compounds present in both the varieties namely MB-87 and S.Bajra 2011. Main compounds that were found were hexanal, heptanal, 2,4-Heptadienal, nonanal, 2,4-Decadienal, tridecanal. Benzene derivitves that were identified include 1,2,4,5-tetramethylbenzene, 2Methylnaphthalene, 1,6-Dimethylnaphthalene, phenanthrene. Alcohols that were discovered include 1Hexanol, 1-Octen-3-ol, 1-Octanol, 8-Dodecen-1-ol. Ketonic compounds that were identified include 2heptanone, 2,5-octanedione, acetophenone, 3 nonen-2one, 2-heptadecanone. Main hydrocarbon compounds that were discovered are dodecane, tridecane, hexadecane, octadecane. Acidic compounds that were distinguished include Tetradecanoic acid, pentadecanoic acid, hexadecanoic acid. Main ester compounds that were 
identified include Propyl benzoate, Benzoic acid, butyl ester, Hexadecanoic acid, methyl ester. Heterocycles that were identified includes 3-Furaldehyde, Furfural, 1-(2Furanyl)-ethanone, 2 Pentylfuran. Sulphur containing compounds that were present include Diethyl disulphide, Benzothiazole. The results that were obtained were in accordance to the research outcomes of Damjan et al. (2009) and Liu et al. (2012).

Volatile compounds of sorghum: Aldehydes were the main compounds present in all the varieties namely Chengari, JS-2002, JS-263, F-114, PC-1, MR-Sorghum and Sandal Bar. Main compounds that were found were hexanal, heptanal, 2,4-Heptadienal, nonanal, decanal and tridecanal. Benzene derivitves that were identified include 1,2,4,5-tetramethylbenzene, 2-Methylnaphthalene, mxylene, phenanthrene and toluene. Alcohols that were discovered include Propan-1-ol, 1-Hexanol, 2,3Butanediol, 1-Octanol and nonan-1-ol. Ketonic compounds that were identified include 2-heptanone, 2,5octanedione, 3 nonen-2-one. Main hydrocarbon compounds that were discovered are dodecane, tridecane, hexadecane, octadecane. Acidic compounds that were distinguished include Tetradecanoic acid, acetic acid, hexadecanoic acid and isobutyric acid. Main ester compounds that were identified include Propyl benzoate, ethyl acetate andpropyl acetate. Heterocycles that were identified includes 3-Furaldehyde, Furfural and 2 Pentylfuran. Sulphur containing compounds that were present include Diethyl sulfide and diethyl disulphide. The results that were obtained were in accordance to the research outcomes of Lasekan et al. (1997) and Lyumugabe et al. (2013).

Table 5 Volatile compounds of millet varieties

\begin{tabular}{|c|c|c|c|}
\hline \multirow[b]{2}{*}{ Serial No. } & \multirow[b]{2}{*}{ Compound name } & \multicolumn{2}{|c|}{ Retention times } \\
\hline & & MB-87 & S. Bajra 2011 \\
\hline & Aldehydes & & \\
\hline 1 & Hexanal & 21.798 & 22.103 \\
\hline 2 & Heptanal & -- & 17.557 \\
\hline 3 & (E,E)-2,4-Heptadienal & 14.911 & 15.334 \\
\hline 4 & Nonanal & 16.748 & -- \\
\hline 5 & (E,E)-2,4-Decadienal & -- & 20.459 \\
\hline 6 & Tridecanal & 17.89 & -- \\
\hline & Benzene derivatives & & \\
\hline 1 & 1,2,4,5-Tetramethylbenzene & 23.784 & 23.946 \\
\hline 2 & 2-Methylnaphthalene & -- & 25.079 \\
\hline 3 & Phenanthrene & 26.038 & 25.166 \\
\hline & Alcohols & & \\
\hline 1 & 1-Hexanol & 24.170 & -- \\
\hline 2 & 1-Octen-3-ol & 23.298 & 23.734 \\
\hline 3 & 1-Octanol & -- & 23.852 \\
\hline & Ketones & & \\
\hline 1 & 2-Heptanone & 26.287 & -- \\
\hline 2 & 2,5-Octanedione & 26.991 & 27.520 \\
\hline 3 & Acetophenone & 29.338 & 28.609 \\
\hline 4 & 3-Nonen-2-one & -- & 29.662 \\
\hline & Hydrocarbons & & \\
\hline 1 & Dodecane & 31.361 & 32.071 \\
\hline 2 & Tridecane & 33.410 & -- \\
\hline 3 & Hexadecane & 34.079 & 34.823 \\
\hline & Acids & & \\
\hline 1 & Tetradecanoic acid & 35.789 & -- \\
\hline 2 & Pentadecanoic acid & -- & 34.612 \\
\hline 3 & Hexadecanoic acid & 10.054 & 8.454 \\
\hline & Esters & & \\
\hline 1 & Propyl benzoate & -- & 13.043 \\
\hline 2 & Benzoic acid, butyl ester & 9.575 & -- \\
\hline 3 & Hexadecanoic acid, methyl ester & 5.397 & 5.908 \\
\hline & Heterocycles & & \\
\hline 1 & 3-Furaldehyde & 3.280 & 3.952 \\
\hline 2 & Furfural & -- & 2.321 \\
\hline 3 & 1-(2-Furanyl)-ethanone & 1.680 & 1.113 \\
\hline & Sulphur-containing & & \\
\hline 1 & Diethyl disulphide & 1.742 & -- \\
\hline 2 & Benzothiazole & 1.649 & 4.089 \\
\hline
\end{tabular}


Table 6: Volatile compounds of sorghum varieties

\begin{tabular}{|c|c|c|c|c|c|c|c|c|}
\hline \multirow[b]{2}{*}{$\begin{array}{l}\text { Sr. } \\
\text { No. }\end{array}$} & \multirow[b]{2}{*}{ Compound name } & \multicolumn{7}{|c|}{ Retention times (min) } \\
\hline & & Chengari & JS-2002 & JS-263 & F-114 & PC-1 & $\begin{array}{c}\text { MR- } \\
\text { Sorghum }\end{array}$ & $\begin{array}{c}\text { Sandal } \\
\text { Bar }\end{array}$ \\
\hline & Aldehydes & & & & & & & \\
\hline 1 & Hexanal & 3.330 & 3.716 & 3.821 & 4.220 & 4.961 & 5.085 & 5.160 \\
\hline 2 & Heptanal & 6.150 & 6.219 & 6.312 & 6.387 & 6.511 & 6.841 & 6.916 \\
\hline 3 & $(\mathrm{E}, \mathrm{E})-2,4-H e p t a d i e n a l$ & 7.053 & 7.178 & 8.927 & 9.363 & 9.668 & 9.730 & 10.179 \\
\hline 4 & Nonanal & 11.953 & 12.532 & 12.819 & 13.068 & 13.199 & 13.622 & 14.045 \\
\hline 5 & Decanal & 14.195 & 14.487 & 14.799 & 15.085 & 15.384 & 15.677 & 15.851 \\
\hline 6 & Tridecanal & 16.231 & 16.511 & 16.585 & 16.872 & 16.997 & 17.059 & 17.408 \\
\hline & Benzene derivatives & & & & & & & \\
\hline 1 & 1,2,4,5-Tetramethylbenzene & 17.582 & 17.607 & 17.682 & 18.049 & 18.136 & 18.834 & 18.915 \\
\hline 2 & 2-Methylnaphthalene & 19.768 & 20.029 & 20.309 & 20.527 & 20.577 & 21.150 & 21.586 \\
\hline 3 & rn-Xylene & 21.660 & 22.215 & 22.700 & 23.454 & 23.883 & 25.447 & 26.206 \\
\hline 4 & Phenanthrene & 26.984 & 28.161 & 28.752 & 30.197 & 31.654 & 33.111 & 33.323 \\
\hline 5 & Toluene & 34.294 & 34.543 & 34.674 & 35.072 & 35.521 & 33.250 & 33.750 \\
\hline & Alcohols & & & & & & & \\
\hline 1 & Propan-1-ol & 2.240 & 2.321 & 2.794 & 3.137 & 3.280 & 3.772 & 3.952 \\
\hline 2 & 1-Hexanol & 4.295 & 5.291 & 5.397 & 5.908 & 5.976 & 7.159 & 7.937 \\
\hline 3 & 2,3-Butanediol & 8.105 & 8.454 & 8.759 & 9.450 & 9.575 & 10.372 & 11.374 \\
\hline 4 & Octan-1-ol & 12.526 & 13.043 & 14.706 & 15.334 & 15.864 & 16.412 & 16.748 \\
\hline 5 & Nonan-1-ol & 16.904 & 17.557 & 18.049 & 18.311 & 20.204 & 21.144 & 21.536 \\
\hline & Ketones & & & & & & & \\
\hline 1 & 2-Heptanone & 21.686 & 21.729 & 21.959 & 22.171 & 22.277 & 23.298 & 23.529 \\
\hline 2 & 2,5-Octanedione & 24.108 & 24.326 & 24.456 & 24.699 & 24.973 & 25.079 & 25.278 \\
\hline 3 & 3-Nonen-2-one & 26.287 & 26.474 & 26.991 & 27.520 & 28.609 & 29.338 & 29.711 \\
\hline & Hydrocarbons & & & & & & & \\
\hline 1 & Dodecane & 30.241 & 30.901 & 31.187 & 31.361 & 32.071 & 32.725 & 33.092 \\
\hline 2 & Tridecane & 33.410 & 33.535 & 34.107 & 34.823 & 35.079 & 35.216 & 35.789 \\
\hline 3 & Hexadecane & 36.125 & 36.417 & 36.884 & 35.250 & 36.250 & 36.653 & 36.750 \\
\hline 4 & Octadecane & 1.150 & 1.325 & 1.343 & 1.991 & 2.052 & 2.190 & 3.716 \\
\hline & Acids & & & & & & & \\
\hline 1 & Tetradecanoic acid & 4.220 & 4.961 & 5.085 & 5.932 & 6.088 & 6.219 & 6.387 \\
\hline 2 & Acetic acid & 6.511 & 6.841 & 6.916 & 7.178 & 8.927 & 9.363 & 10.179 \\
\hline 3 & Hexadecanoic acid & 10.876 & 11.953 & 12.532 & 12.819 & 13.068 & 13.199 & 13.622 \\
\hline 4 & Isobutyric acid & 14.120 & 14.276 & 14.487 & 14.649 & 15.085 & 15.633 & 15.714 \\
\hline & Esters & & & & & & & \\
\hline 1 & Propyl benzoate & 15.851 & 15.982 & 16.125 & 16.331 & 16.586 & 16.760 & 16.953 \\
\hline 2 & Ethyl acetate & 17.364 & 17.408 & 17.607 & 17.682 & 18.049 & 18.136 & 18.834 \\
\hline 3 & Propyl acetate & 19.450 & 19.531 & 19.680 & 20.029 & 20.527 & 20.776 & 20.944 \\
\hline & Heterocycles & & & & & & & \\
\hline 1 & 3-Furaldehyde & 21.287 & 21.586 & 21.660 & 22.127 & 22.420 & 22.700 & 23.211 \\
\hline 2 & Furfural & 24.338 & 25.447 & 26.411 & 26.984 & 28.161 & 28.752 & 29.823 \\
\hline 3 & 2-Pentylfuran & 30.197 & 31.224 & 31.934 & 32.420 & 33.111 & 33.572 & 34.294 \\
\hline & Sulphur-containing & & & & & & & \\
\hline 1 & Dimethyl sulfide & 34.674 & 35.072 & 35.521 & 31.750 & 34.770 & 33.250 & 34.570 \\
\hline 2 & Diethyl disulphide & 35.520 & 36.778 & 36.342 & 33.768 & 35.763 & 34.543 & 35.250 \\
\hline
\end{tabular}

\section{Conclusion}

Sorghum and millet are neglected cereals and can become important staple crops not only for the under developed, drought and famine affected countries but can also for the developed countries. Sorghum and millet characterization have depicted that these have nutritional profile comparable to wheat and other cereals. In fact these are the good and effective sources of proteins, fiber, fatty acid and many other nutritional components. In this research fatty acid profile of sorghum and millet showed that these are rich in palmitic acid, oleic acid, linolenic and linoleic acid, stearic acid, myristic acid, behenic acid, erucic acid. The volatile profile of sorghum and millet have shown that these belong to the various aromatic groups, aliphatic, sulpher groups, acids, aldehydic, ketonic, benzene derivatives, esters and hydrocarbons.
Thus these two important and potent cereals have to be prioritized and given the due attention in using as staple as well as in drought and famine conditions.

\section{Acknowledgement}

Special thanks to Higher Education Commission for funding this research project under National research Programme for Universities (NRPU).

\section{References}

AACC. 2000. Approved Methods of American Association of Cereal Chemists. The American Association of Cereal Chemists, Inc. St. Paul. Minnesota, USA.

Aronson WJ, Glaspy JA, Reddy ST, Reese D, Heber D, Bagga J 2001. Modulation of omega-3/omega-6 polyunsaturated ratios with dietary fish oils in men with prostate cancer. Urology 58:283-288. 
Awika JM, Rooney LW. 2004. Sorghum phytochemicals and their potential aspects on human health. Phytochem 65: 1199-1221.

Belton PS, Taylor JRN. 2004. Sorghum and millets: protein sources for Africa. Trends Food Sci Technol 15: 94-98.

Chethan S, Malleshi NG. 2007. Finger millet polyphenols: characterization and their nutraceutical potential. Am J Food Technol 2: 582-592.

Damjan J, Dragana K, Samo K, Helena P. 2009. Identification of buckwheat (Fagopyrum esculentum Moench) aroma compounds with GC-MS. Food Chem 112: 120-124.

Hargrove RL, Etherton TD, Pearson TA, Harrison EH, KrisEtherton PM. 2001. Low-fat and high-monounsaturated fat diets decrease human low-density lipoprotein oxidative susceptibility in vitro. J Nutri 131: 1758-1763.

Iso HS, Sato U, Umemura M, Kudo K, Koike A, Kitamura H, Imano T, Okamura Y, Shimamoto T. 2002. Linoleic acid, other fatty acids, and the risk of stroke. Stroke 33: 2086-2093.

Jingke L, Tang X, Zhang Y, Zhao W. 2012. Determination of the Volatile Composition in Brown Millet, Milled Millet and Millet Bran by Gas Chromatography/Mass Spectrometry. Molecul. 17: 2271-2282.

Lakshmi KP. Sumathi S. 2002. Effect of consumption of finger millet on hyperglycemia in non-insulin dependent diabetes mellitus (NIDDM) subjects. Plant Food Hum. Nutr.57: 205-213.

Lasekan OO, Lasekan WO, Idowu MA. 1997. Flavour volatiles of 'malt beverage' from roasted Sorghum. Food Chem. 58: 341344.

Liu J, Tang Y, Zhao W. 2012. Determination of the volatile composition in brown millet, milled millet and millet bran by gas chromatography/mass spectrometry. Molecules, 17: 22712282.

Lovis LJ. 2003. Alternatives to wheat flour in baked goods. Cereal Foods World, 48: 61-63.
Maha AMA, Abdullahi HET, AbdelWahab HA. 2003. Effect of fermentation on the in vitro protein digestibility of pearl Millet. Food Chem. 80: 51-54.

Mehmood S, Orhan I, Ahsan Z, Aslan S, Gulfraz M. 2008. Fatty acid composition of seed oil of different Sorghum bicolor varieties. Food Chem. 109: 855-859.

Patil V, Gislerod HR. 2006. The importance of omega-3 fatty acids in diet. Current Sci. 90: 908-909.

Ragaee S, Abdel-Aal ESM, Noaman M. 2006. Antioxidant activity and nutrient composition of selected cereals for food use. Food Chem., 98: 32-38.

Rai S, Kaur A, Singh B. 2011. Quality characteristics of gluten free cookies prepared from different flour combinations. Journal of Food Science Technology, DOI 10.1007/s13197-011-0547-1.

Rehman S, Ahmad MM, Bhatti IA, Shafique R, Din GM, Murtaza MA. 2006. Effect of pearling on physico-chemical, rheological characteristics and phytate content of wheat-sorghum flour. Pak J Bot 38: 711-719.

Rooney LW, Waniska RD. 2000. Sorghum food and industrial utilization. In: Smith, C.W. and Frederiksen, R.A. (Eds.), Sorghum: Origin, History, Technology, and Production. Wiley, New York, pp. 689-729.

Ryan E, Galvin K, O’Connor TP, Maguire AR, O’Brien NM. 2007. Phytosterol, Squalene, Tocopherol Content and Fatty Acid Profile of Selected Seeds, Grains, and Legumes. Plant Foods Hum. Nutr. 62: 85-91.

Saha S, Gupta A, Singh SRK, Bharti N, Singh KP, Mahajan V, Gupta HS. 2011. Compositional and varietal influence of finger millet flour on rheological properties of dough and quality of biscuit. LWT - Food SciTechnol 44: 616-621.

Sikwese FE, Duodu KG. 2007. Antioxidant effect of a crude phenolic extract from sorghum bran in sunflower oil in the presence of ferric ions. Food Chem. 104: 324-331.

Yaqoob P. 2002. Monounsaturated fatty acids and immune function. Europ. J. Clinical Nutri, 56: 9-13. 